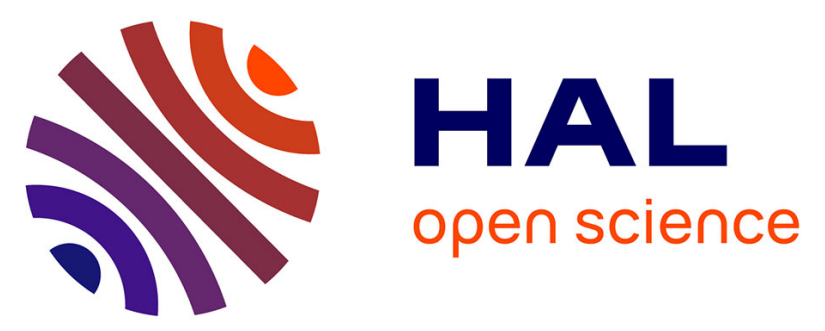

\title{
The role of ligand-field states in the ultrafast photophysical cycle of the prototypical iron(II) spin-crossover compound $[\mathrm{Fe}(\mathrm{ptz}) 6](\mathrm{BF} 4) 2$
}

Andrea Marino, Pradip Chakraborty, Marina Servol, Maciej Lorenc, Eric Collet, Andreas Hauser

\section{To cite this version:}

Andrea Marino, Pradip Chakraborty, Marina Servol, Maciej Lorenc, Eric Collet, et al.. The role of ligand-field states in the ultrafast photophysical cycle of the prototypical iron(II) spin-crossover compound [Fe(ptz)6](BF4)2. Angewandte Chemie International Edition, 2014, 53 (15), pp.3863-3867, 10.1002/anie.201310884. 10.1002/anie.201310884 . hal-00959758

\section{HAL Id: hal-00959758 https://hal.science/hal-00959758}

Submitted on 18 Mar 2014

HAL is a multi-disciplinary open access archive for the deposit and dissemination of scientific research documents, whether they are published or not. The documents may come from teaching and research institutions in France or abroad, or from public or private research centers.
L'archive ouverte pluridisciplinaire HAL, est destinée au dépôt et à la diffusion de documents scientifiques de niveau recherche, publiés ou non, émanant des établissements d'enseignement et de recherche français ou étrangers, des laboratoires publics ou privés. 


\title{
The role of ligand-field states in the ultrafast photophysical cycle of the prototypical iron(II) spin-crossover compound $\left[\mathrm{Fe}(\mathrm{ptz})_{6}\right]\left(\mathrm{BF}_{4}\right)_{2}$ **
}

\author{
Andrea Marino, ${ }^{a+}$ Pradip Chakraborty, ${ }^{b+}$ Marina Servol $^{a}$, Maciej Lorenc, ${ }^{a}$ Eric Collet, ${ }^{a}$ \\ and Andreas Hauser*b

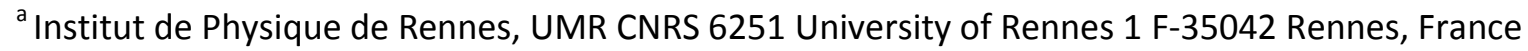 \\ ${ }^{b}$ Département de chimie physique, Université de Genève, 30 Quai Ernest-Ansermet Ch-1211 Genève \\ 4 Switzerland
}

Fax: +41223796103

E-mail: andreas.hauser@unige.ch

[+] These authors contributed equally to this work.

This work was financially supported by the Swiss National Science Foundation (Grant No. 200020_137567), the CNRS, Région Bretagne, the ANR (09-BLAN-0212), and Europe (FEDER).

\begin{abstract}
Light-induced excited spin state trapping (LIESST) in iron(II) spin-crossover compounds, i.e., the light-induced population of the high-spin $(S=2)$ state below the thermal transition temperature, was discovered thirty years ago. For irradiation into metal-ligand charge transfer $(M L C T)$ bands of the low-spin $(S=0)$ species the acknowledged sequence takes the system from the initially excited ${ }^{l} M L C T$ to the high-spin state via the ${ }^{3} M L C T$ state within $\sim 150 \mathrm{fs}$, thereby bypassing lowlying ligand-field $(L F)$ states. Nevertheless, these play role, as borne out by the observation of LIESST and reverse-LIESST on irradiation directly into the LF bands for systems with only high-energy MLCT states. Herein we elucidate the ultrafast reverse-LIESST pathway by identifying the lowest energy $S=1$ LF state as intermediate state with a lifetime of 39 ps for the light-induced high-spin to low-spin conversion on irradiation into the spin-allowed LF transition of the high-spin species in the NIR.
\end{abstract}

In 1982 McGarvey and Lawthers reported that the equilibrium between the spin states of iron(II) spin-crossover complexes in solution at around room temperature can be photophysically perturbed via irradiation into the intense spin and parity allowed metal-ligand charge transfer $\left({ }^{1}\right.$ MLCT) absorption bands of the low-spin (LS) species. ${ }^{[1]}$ This was followed by the discovery of light-induced excited spin state trapping (LIESST) in the solid state, that is, the population of the high-spin (HS) state as long-lived metastable state at low temperature upon irradiation into the above mentioned ${ }^{1}$ MLCT bands as well as into ligand-field (LF) bands. ${ }^{[2]}$ Initially, these effects served to study the $\mathrm{HS}\left({ }^{5} \mathrm{~T}_{2}\left(\mathrm{t}_{2 \mathrm{~g}}{ }^{4} \mathrm{e}_{\mathrm{g}}{ }^{2}\right)\right) \prod \mathrm{LS}\left({ }^{1} \mathrm{~A}_{1}\left(\mathrm{t}_{2 \mathrm{~g}}{ }^{6}\right)\right)$ relaxation dynamics in solution ${ }^{[3]}$ as well as in the solid state, where cooperative effects are of interest. ${ }^{[4]}$

Ultrafast pump-probe spectroscopy including structural probes on iron(II) spin-crossover ${ }^{[5]}$ and low-spin complexes ${ }^{[6]}$ in solution with low-lying MLCT states showed that the double intersystem crossing from the initially excited ${ }^{1}$ MLCT state to the HS state occurs with quantum efficiencies near unity, takes only $\sim 150 \mathrm{fs}$, and proceeds via the ${ }^{3}$ MLCT state, thus bypassing the low-lying singlet and triplet LF states. For irradiation into the ${ }^{1}$ MLCT bands Chang et al. ${ }^{[7]}$ laid the theoretical base for this, and Collet et al. ${ }^{[8]}$ showed that at short delays this sequence of events is also valid for the solid state, that, however, due to the elastic interactions, lattice dynamics result in important after effects. In a recent study on a HS complex in solution at room temperature, Galle et al. ${ }^{[9]}$ showed that upon irradiation into the weaker ${ }^{5} \mathrm{MLCT}$ band, the LS state becomes likewise populated through MLCT intersystem crossing.

The role of LF states in transition metal photophysics of $\mathrm{d}^{6}$ systems such as ruthenium(II) and iron(II) complexes is nevertheless crucial, and that they are by no means innocent is borne out by the discovery of LIESST upon irradiation into the spin-allowed LF absorption bands of the LS species of the spin-crossover compound $\left[\mathrm{Fe}(\mathrm{ptz})_{6}\right]\left(\mathrm{BF}_{4}\right)_{2}(\mathrm{ptz}=1$ propyltetrazole), which has no low-energy MLCT states. ${ }^{[4]}$ In Figure 1 the spin-allowed and the spin-forbidden LF transitions 
of both the LS and the HS species are assigned. This study also revealed that the thermal relaxation from the trapped HS state sets in at around $50 \mathrm{~K}$, and that at $10 \mathrm{~K}$ the trapped system can be pumped back to the LS state by irradiation into the spin allowed LF band of the HS species in the near IR (reverse LIESST). ${ }^{[4]}$

Based on the experimentally determined values of the overall quantum efficiencies of LIESST and reverse-LIESST at 10 $\mathrm{K}$ of 0.8 and 0.1 in $\left[\mathrm{Fe}(\mathrm{ptz})_{6}\right]\left(\mathrm{BF}_{4}\right)_{2}$, respectively, and the fact that LIESST is also observed on irradiation directly into the spin-forbidden transitions of the LS species, the scheme for the different light-induced processes in Figure 2 was proposed, and a value of 4:1 was estimated for the ${ }^{3} \mathrm{~T}_{1} \rightarrow{ }^{5} \mathrm{~T}_{2} /{ }^{3} \mathrm{~T}_{1} \rightarrow{ }^{1} \mathrm{~A}_{1}$ branching ratio at $10 \mathrm{~K} .{ }^{[4]}$

For the neat title compound, the near IR and visible spectral region is thus dominated by the weak LF transitions, the rise to the intense MLCT bands being observed only above $30000 \mathrm{~cm}^{-1}$. The latter can be conveniently studied in a dilute mixed crystal of composition $\left[\mathrm{Zn}_{1-\mathrm{x}} \mathrm{Fe}_{\mathrm{x}}(\mathrm{ptz})_{6}\right]\left(\mathrm{BF}_{4}\right)_{2}, \mathrm{x}=0.01$. The corresponding absorption spectrum, included in Figure 1, is strongly temperature dependent. The intense low-temperature band with the absorption maximum at lower energy can be readily assigned to the ${ }^{1}$ MLCT transition of the LS species. As the thermal population of the HS state sets in, it looses intensity, till at room temperature it is entirely replaced by the weaker ${ }^{5}$ MLCT band of the HS species centred at slightly higher energy. The intensity of the ${ }^{1}$ MLCT band at the band maximum thus monitors the HS fraction $\gamma_{\mathrm{HS}}$ effectively. Figure 3 shows the thermal spin transition curves with a gradual transition around $\mathrm{T}_{1 / 2}=92 \mathrm{~K}$ for the dilute system and at $\mathrm{T}_{1 / 2}=125 \mathrm{~K}$ for the high-symmetry crystallographic phase ${ }^{[10]}$ of the neat title compound. The latter is much steeper due to cooperative effects. $^{[4]}$

LIESST and reverse-LIESST can be used to record HS П LS relaxation curves as shown in Figures $4 \mathrm{a}$ and $\mathrm{b}$ for irradiation at $488 \mathrm{~nm}\left(20500 \mathrm{~cm}^{-1}\right)$ and $104 \mathrm{~K}$, and at $830 \mathrm{~nm}\left(12050 \mathrm{~cm}^{-1}\right)$ and $120 \mathrm{~K}$ for $\left[\mathrm{Zn}_{1-\mathrm{x}} \mathrm{Fe}_{\mathrm{x}}(\mathrm{ptz})_{6}\right]\left(\mathrm{BF}_{4}\right)_{2}, \mathrm{x}=0.1$, respectively. For the former, the bleaching of the first spin-allowed LF transition of the LS species at $530 \mathrm{~nm}\left(18800 \mathrm{~cm}^{-1}\right)$ was monitored. For the latter, the transient absorption of the ${ }^{1}$ MLCT band at $305 \mathrm{~nm}\left(32790 \mathrm{~cm}^{-1}\right)$ allowed for a sensitive detection of the light-induced LS population. Figure $4 \mathrm{c}$ shows the observed HS П LS relaxation rate constant $\mathrm{k}_{\mathrm{obs}}=\mathrm{k}_{\mathrm{HL}}+\mathrm{k}_{\mathrm{LH}}$ on a logarithmic scale against $\mathrm{T}^{-1}$ determined via LIESST below $120 \mathrm{~K}$ and via reverse LIESST from 110 to $180 \mathrm{~K}$ in the same system. Above $160 \mathrm{~K}$, the quantum efficiency for reverse-LIESST rapidly drops to zero. The observed relaxation rate constant spans 12 orders of magnitude in the experimentally accessible temperature range. At high temperature the relaxation is thermally activated, whereas at low temperatures it tends towards a quantum mechanical tunnelling process with $\mathrm{k}_{\mathrm{obs}}=$ $\mathrm{k}_{\mathrm{HL}}(\mathrm{T} \rightarrow 0)<10^{-6} \mathrm{~s}^{-1} \cdot[4]$

With the above, the optimal conditions for ultrafast pump-probe experiments can be assessed. They were thus performed at $125 \mathrm{~K}$ on a mixed crystal with $\mathrm{x}=0.1$. This temperature was specifically chosen because at $125 \mathrm{~K}$ the equilibrium HS fraction is $\sim 85 \%$, and the reverse-LIESST quantum efficiency is still reasonably high, so that pumping at $830 \mathrm{~nm}$ can be expected to be as effective as possible. At the same time the HS $\Pi$ LS relaxation occurs within $\sim 0.3 \mathrm{~ms}$ allowing one to work at the full repetition rate of $1 \mathrm{kHz}$ of the laser system in order to make use of efficient signal averaging. ${ }^{[8 c]}$ For the comparatively high value of $\mathrm{x}$, a very small light-induced LS fraction gives rise to a sizeable signal at the maximum of the intense ${ }^{1}$ MLCT absorption. Thus the low absorption cross section at the excitation wavelength is compensated by the high concentration and the sensitivity to the transient population of the LS state at the probe wavelength of $300 \mathrm{~nm}$. Since at $125 \mathrm{~K}$ the low-spin fraction is still 15\%, the same experimental conditions can be maintained for LIESST irradiation at $530 \mathrm{~nm}$.

Figure 5a shows the kinetic trace of $\Delta \mathrm{OD}$ at $300 \mathrm{~nm}$ following $100 \mathrm{fs}$ irradiation of $\left[\mathrm{Zn}_{1-\mathrm{x}} \mathrm{Fe}_{\mathrm{x}}(\mathrm{ptz})_{6}\right]\left(\mathrm{BF}_{4}\right)_{2}, \mathrm{x}=0.1$, at 830 $\mathrm{nm}$, that is, into the spin-allowed ${ }^{5} \mathrm{~T}_{2} \rightarrow{ }^{5} \mathrm{E} \mathrm{LF}$ transition of the HS state $\left(\varepsilon_{830}=5 \mathrm{M}^{-1} \mathrm{~cm}^{-1}\right)$. Immediately following the excitation pulse, a sharp and strong transient absorption peak is observed, which decays with a time constant of $\tau_{1}=1.7(2) \mathrm{ps}$ (see inset) to a minimum, from which the absorption increases again with a time constant $\tau_{2}=39(3) \mathrm{ps}$. The plateau reached at the end of the rise does not decay within the range of the ultrafast setup. It thus corresponds to the excited state absorption (ESA) of the light-induced population of the $\operatorname{LS}\left({ }^{1} \mathrm{~A}_{1}\right)$ state decaying with the above mentioned time constant of $0.3 \mathrm{~ms}$. The $39 \mathrm{ps}$ of the rise to the plateau therefore correspond to the arrival time at the $\operatorname{LS}\left({ }^{1} \mathrm{~A}_{1}\right)$ state. The instrumental response function (IRF) of the setup is $150 \mathrm{fs}$, the decay of the initial signal within $1.7 \mathrm{ps}$ is therefore real and the minimum in the transient signal corresponds to the population of an intermediate state. At the probe wavelength of $300 \mathrm{~nm}$, the vertical ${ }^{1}$ MLCT transition from the $\operatorname{LS}\left({ }^{1} \mathrm{~A}_{1}\right)$ state has the highest extinction coefficient because this state has the shortest metal-ligand bond length, but as the quantum efficiency of reverse-LIESST is quite low and decreasing with increasing temperature, the amplitude of the plateau corresponding to its light-induced population is not very large. The initially excited state by the laser pulse is the ${ }^{5} \mathrm{E}\left(\mathrm{t}_{2 \mathrm{~g}}{ }^{3} \mathrm{e}_{\mathrm{g}}{ }^{3}\right) \mathrm{LF}$ state. In the Franck-Condon state at time zero, its MLCT transition is expected to have an extinction coefficient in the range of the ${ }^{5}$ MLCT transition from the $\mathrm{HS}\left({ }^{5} \mathrm{~T}_{2}\right)$ state but to occur at lower energy (see Figures 1 and 2), that is, at around $30^{\prime} 000 \mathrm{~cm}^{-1}$, and is thus monitored at the probe wavelength. It decays either via internal conversion back to the $\mathrm{HS}\left({ }^{5} \mathrm{~T}_{2}\right)$ state or to the intermediate state. Based on energetic and geometric considerations, the intermediate state of lower energy than the ${ }^{5} \mathrm{E}$ state can only be the ${ }^{3} \mathrm{~T}_{1}\left(\mathrm{t}_{2 \mathrm{~g}} \mathrm{e}_{\mathrm{g}}{ }^{1}\right)$ LF state. ${ }^{[1]}$ The transient signal at very short times thus corresponds to ESA from the hot ${ }^{5} \mathrm{E}$ state and its fast decay to a combination of vibrational cooling, internal conversion and intersystem crossing. Only the last one will result in the transient ESA at the minimum, and this therefore corresponds to the ${ }^{3} \mathrm{MLCT}$ absorption from the ${ }^{3} \mathrm{~T}_{1}$, which is spin-allowed and has an extinction coefficient that is intermediate between the ones of the spin-allowed ${ }^{5}$ MLCT and ${ }^{1}$ MLCT bands from their respective LF states. The $39 \mathrm{ps}$ are much longer than vibrational cooling in the solid state, therefore the second step in the cascade occurs from the thermally relaxed intermediate state. 
Figure $5 \mathrm{~b}$ shows the kinetic trace as $\Delta \mathrm{OD}$ at $300 \mathrm{~nm}$ following $100 \mathrm{fs}$ irradiation of $\left[\mathrm{Zn}_{1-\mathrm{x}} \mathrm{Fe}_{\mathrm{x}}(\mathrm{ptz})_{6}\right]\left(\mathrm{BF}_{4}\right)_{2}, \mathrm{x}=0.1$, at 530 $\mathrm{nm}$, that is, into the spin-allowed ${ }^{1} \mathrm{~A}_{1} \rightarrow{ }^{1} \mathrm{~T}_{1} \mathrm{LF}$ transition of the LS state $\left(\varepsilon_{530}=25 \mathrm{M}^{-1} \mathrm{~cm}^{-1}\right)$. The ESA signal at $\mathrm{t}=0$ is attributed to absorption from the hot ${ }^{1} \mathrm{~T}_{1}$ state. It decays with a time constant $\tau_{1}<$ IRF of the setup, and is replaced by a negative signal. Bleaching must be attributed to the instantaneous depletion of the LS fraction from its equilibrium value of $15 \%$ at $125 \mathrm{~K}$, as the $\operatorname{LS}\left({ }^{1} \mathrm{~A}_{1}\right)$ state is the most strongly absorbing species present, except for absorption from the hot ${ }^{1} \mathrm{~T}_{1}$ state. A second, slower process with a time constant $\tau_{2}=1.2(2)$ ps leads to a still more negative signal, which persists for the duration of the experiment and decays with the time constant of $\sim 0.3 \mathrm{~ms}$ of the HS $\Pi$ LS relaxation at $125 \mathrm{~K}$. Does the slower process indicate population of an intermediate state or does it correspond to vibrational cooling in the HS state as the final state of the fast relaxation cascade? Given that (i) the ${ }^{5}$ MLCT intensity at the probe wavelength is much lower than the ${ }^{1}$ MLCT intensity, (ii) ${ }^{3}$ MLCT intensities from triplet states are expected to be in between the two, and (iii) the overall quantum efficiency of the light-induced LS $\rightarrow$ HS conversion is high, the former is more probable. However, the $1.2 \mathrm{ps}$, are much shorter than the $39 \mathrm{ps}$ attributed to the lifetime of the ${ }^{3} \mathrm{~T}_{1}$ state in reverse-LIESST, and therefore this state cannot be the intermediate state for LIESST upon LF excitation. According to Ordejon et al. ${ }^{[11]}$ direct ${ }^{1} \mathrm{~T}_{1} \rightarrow{ }^{5} \mathrm{~T}_{2}$ intersystem crossing with $\Delta \mathrm{S}=2$ is unlikely because of very weak spin-orbit coupling between these two states. But spin-orbit coupling in conjunction with vibronic coupling to a non-totally symmetric mode couples the higher-energy ${ }^{3} \mathrm{~T}_{2}$ state quite strongly, and indeed more strongly than the ${ }^{3} \mathrm{~T}_{1}$ state, to the ${ }^{1} \mathrm{~T}_{1}$ state. ${ }^{[1]} \mathrm{The}{ }^{3} \mathrm{~T}_{2}$ state, in turn, is strongly coupled to the ${ }^{5} \mathrm{~T}_{2}$ state, and thus it is the natural candidate as intermediate state for LIESST via LF excitation.

Do the above results verify the picture proposed in Ref. [4] or does it need modifying? Qualitatively the picture remains valid, the low-lying triplet LF states do play a role in the photophysical cycle of $\left[\mathrm{Fe}(\mathrm{ptz})_{6}\right]\left(\mathrm{BF}_{4}\right)_{2}$, and at least for reverseLIESST, the double intersystem crossing is sequential. The individual quantum efficiencies, and possibly the branching ratio at the ${ }^{3} \mathrm{~T}_{1}$ state given in that reference may need to be revised. These were derived based on the observation of overall quantum efficiencies and the assumption that all intersystem crossing processes follow Fermi's Golden Rule, that is, that vibrational cooling in each state is faster than its lifetime, and that therefore its fate is not influenced by the way it is populated. This is correct for the ${ }^{3} \mathrm{~T}_{1}$ state when populated with little excess energy via reverse-LIESST, that is, from the ${ }^{5} \mathrm{E}$ state upon ${ }^{5} \mathrm{~T}_{2} \rightarrow{ }^{5} \mathrm{E}$ excitation. Its lifetime is longer than vibrational cooling, and the branching ratio is expected to follow the semi-classical behaviour of a non-adiabatic multi-phonon process occurring between two well-defined Born-Oppenheimer states, ${ }^{[12]}$ as also found for the HS $\rightarrow$ LS relaxation itself. The fact that the action spectrum for reverse-LIESST follows the ${ }^{5} \mathrm{~T}_{2} \rightarrow{ }^{5} \mathrm{E}$ absorption band, ${ }^{[4]}$ indicates that the probabilities for the first step are likewise well-defined. This is no longer the case for irradiation into the spin-allowed ${ }^{1} \mathrm{~A}_{1} \rightarrow{ }^{1} \mathrm{~T}_{1} \mathrm{LF}$ transition of the LS species. The relaxation from the initially excited ${ }^{1} \mathrm{~T}_{1}$ to the ${ }^{5} \mathrm{~T}_{2}$ state is as fast as for excitation into the ${ }^{1}$ MLCT bands in the above-mentioned systems. Vibronic coupling between the excited states leads to a breakdown of the Born-Oppenheimer approximation. The electronic and the nuclear wave functions are strongly coupled during the process. The triplet state(s) cannot be identified as true intermediate states, they only serve as mediators dynamically mixed into the electronic function as the system evolves. For a full-scale study we will expand our investigations to different probe wavelengths in the UV, which will allow a more quantitative evaluation of the data, and we will study the temperature dependence of the relevant processes in the present system as well as related systems.

In conclusion, we have investigated the role of the LF states in the photophysical cycle of iron(II) spin-crossover complexes. As for irradiation into MLCT states, the intersystem crossing processes upon irradiation into LF states are ultrafast. These findings are of general importance for the photophysics of transition metal compounds, for instance in comparison with the much studied chromium(III) complexes, ${ }^{[13]}$ or for ruthenium(II) complexes being used in photovoltaic devices $^{[14]}$ or in cancer phototherapy. ${ }^{[15]}$ With regard to the latter, it is interesting to note that in $[\mathrm{Ru}(6$-methyl-2,2'bipyridine $\left.)_{3}\right]^{2+}$ the corresponding ${ }^{3} \mathrm{~T}_{1}$ state has recently been located as intermediate state in the ultrafast quenching of the ${ }^{3}$ MLCT luminescence, the ${ }^{3} \mathrm{~T}_{1}$ state itself having a lifetime of $450 \mathrm{ps} .{ }^{[16]}$

\section{Experimental Section}

$\left[\mathrm{Fe}(\mathrm{ptz})_{6}\right]\left(\mathrm{BF}_{4}\right)_{2}$ and $\left[\mathrm{Zn}_{1-\mathrm{x}} \mathrm{Fe}_{\mathrm{x}}\left(\mathrm{ptz}_{6}\right]\left(\mathrm{BF}_{4}\right)_{2}, \mathrm{x}=0.01\right.$ and 0.1 , were prepared and hexagonal crystals $\left(\sim 3 \times 3 \times 0.2 \mathrm{~mm}^{3}\right)$ were grown as described in Ref. [17]. Variable temperature single crystal absorption spectra were recorded on a Cary 5000 spectrometer with the sample mounted on the cold finger of a closed cycle cryosystem (Janis-Sumitomo) capable of achieving temperatures down to $4 \mathrm{~K}$. Irradiation experiments and HS $\Pi$ LS relaxation measurements on timescales from nanosecond to days were performed as described in Ref. [4]. For reverse-LIESST experiments at T $>120 \mathrm{~K}, 830 \mathrm{~nm}$ light from an OPO (Opotek-Magic Prism) pumped by the third harmonic of a Nd:YAG laser (Quantel Brillant) was used. Ultrafast pump-probe experiments on a crystal of $\left[\mathrm{Zn}_{1-\mathrm{x}} \mathrm{Fe}_{\mathrm{x}}(\mathrm{ptz})_{6}\right]\left(\mathrm{BF}_{4}\right)_{2}, \mathrm{x}=0.1$, were performed as described in Ref. [8c] with $5 \mu \mathrm{J}$ pulse energy focused to $\sim 200 \mu \mathrm{m}$ for pumping and $<0.1 \mu \mathrm{J}$ focused to $\sim 50 \mu \mathrm{m}$ for probing. The sample temperature was controlled with a $\mathrm{N}_{2}$ cryocooler (Oxford Instruments Cryojet). Data treatment involved iterative fitting of a double exponential test function convoluted with a Gaussian IRF function of 150 fs FWHM. 
[1] J. J. McGarvey, I. J. Lawthers, Chem. Soc. Chem. Commun. 1982, 906.

[2] S. Decurtins, P. Gütlich, C. P. Köhler, H. Spiering, A. Hauser, Chem. Phys. Lett. 1984, $105,1$.

[3] C. Brady, J. J. McGarvey, J. K. McCusker, H. Toftlund, D. N. Hendrickson, Top. Curr. Chem. 2004, 235, 1.

[4] A. Hauser, Top. Curr. Chem. 2004, 234, 155, and references therein.

[5] a) N. Huse, H. Cho, K. Hong, L. Jamula, F. M. F. de Groot, T. K. Kim, J. K. McCusker, R. W. Schoenlein, J. Phys. Chem. Lett. 2011, 2, 880, b) N. Huse, T. K. Kim, L. Jamula, J. K. McCusker, F. M. F. de Groot, R. W. Schoenlein, J. Am. Chem. Soc. 2010, 132, 6809, c) A. L. Smeigh, M. Creelman, R. A. Mathies, J. K. McCusker, J. Am. Chem. Soc. 2008, 130, 14105, d) E. A. Juban, A. L. Smeigh, J. E. Monat, J. K. McCusker, Coord. Chem. Rev. 2006, 250, 1783, e) A. Lapini, P. Foggi, L. Bussotti, R. Righini, A. Dei, Inorg. Chim. Acta 2008, 361, 3937.

[6] a) M. Chergui, Dalton Trans. 2012, 41, 13022, b) G. Vanko, P. Glatzel, V.-T. Pham, R. Abela, D. Grolimund, C. N. Borca, S. L. Johnson, C. J. Milne, C. Bressler, Angew. Chem. Int. Ed. 2010, 49, 5910, c) A. Cannizzo, C. G. Milne, C. Consani, W. Gawelda, C. Bressler, F. van Mourik, M. Chergui, Coord. Chem. Rev., 2010, 354, 2677, d) Ch. Bressler, C. Milne, V.-T. Pham, A. ElNahhas, R. M. van der Veen, W. Gawelda, S. Johnson, P. Beaud, D. Grolimund, M. Kaiser, C. N. Borca, G. Ingold, R. Abela, M. Chergui, Science 2009, 323, 489, e) J. Tribollet, G. Gallé, G. Jonusauskas, D. Deldicque, M. Tondusson, J.F. Létard, E. Freysz, Chem. Phys. Lett. 2011, 513, 42.

[7] J. Chang, A. J. Fedro, M. van Veeenendaal, Phys. Rev. B 2010, 82, 075124.

[8] a) R. Bertoni, M. Lorenc, A. Tissot, M. Servol, M.-L. Boillot, E. Collet, Angew. Chem. 2012, 124, 7603, b) E. Collet, N. Moisan, C. Balde, R. Bertoni, E. Trzop, C. Laulhe, M. Lorenc, M. Servol, H. Cailleau, A. Tissot, M.-L. Boillot, T. Graber, R. Henning, P. Coppens, M. Buron-Le Cointe, Phys. Chem. Chem. Phys. 2012, 14, 6192, c) M. Lorenc, C. Balde, W. Kaszub, A. Tissot, N. Moisan, M. Servol, M. Buron-Le Cointe, H. Cailleau, P. Chasle, P. Czarnecki, M.-L. Boillot, E. Collet, Phys. Rev. B 2012, 85, 054302, ; d) A. Marino, M. Servol, R. Bertoni, M. Lorenc, C. Mauriac, J.-F. Létard, E. Collet, Polyhedron 2013, 66, 123.

[9] G. Gallé, G. Jonusauskas, M. Tondusson, C. Mauriac , J. F. Létard, E. Freysz, Chem. Phys. Lett. 2013, 556, 82

[10] J. Kusz, P. Gütlich, H. Spiering, Topics in Curr. Chem. 2004, 234, 129.

[11] B. Ordejon, C. de Graaf, C. Sousa, J. Am. Chem. Soc. 2008, 130, 13961.

[12] E. Buhks, G. Navon, M. Bixon, J. Jortner, J. Am. Chem. Soc. 1980, 102, 2918.

[13] a) J. N. Schrauben, K. L. Dillman, W. F. Beck, J. K. McCusker, Chem. Sci. 2010, 1, 405, b) E. A. Juban., J. K. McCusker, J. Am. Chem. Soc. $2005127(18), 6857$

[14] a) M. Grätzel, Inorg. Chem. 2005, 44, 6841, b) M. Grätzel, Nature 2001, 414, 338.

[15] a) B. S. Howerton, D. K. Heidary, E. C. Glazer, J. Am. Chem. Soc. 2012, 134, 8324, b) E. Wachter, D. K. Heidary, B. S. Howerton, S. Parkin, E. C. Glazer, Chem, Comm. 2012, 48, 9649. c) S. L. H. Higgins, K. J. Brewer, Angew. Chem. Int. Ed. 2012, 51, 11420.

[16] Q. Sun, S. Mosquera-Vasquez, L. M. Lawson Daku, L. Guénée, H. A. Goodwin, E. Vauthey, A. Hauser, J. Am. Chem. Soc. 2013, 135, 13660.

[17] a) P. L. Franke, J. G. Haasnoot, A. P. Zuur, Inorg. Chim. Acta 1982, 59, 5, b) J. Jung, G. Schmitt, L. Wiehl, A. Hauser, K. Knorr, H. Spiering, P. Gütlich, Zeitschrift für Physik B 1996, 100523. 


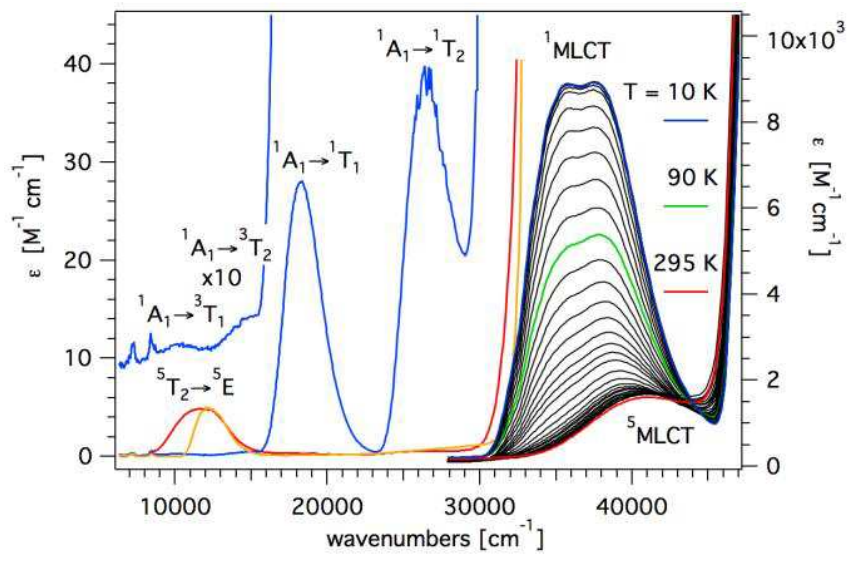

Figure 1. Single crystal absorption spectra of $\left[\mathrm{Fe}\left(\mathrm{ptz}_{6}\right]_{6}\left(\mathrm{BF}_{4}\right)_{2}\right.$ at $10 \mathrm{~K}(-), 295 \mathrm{~K}(--)$ and after irradiation at $530 \mathrm{~nm}(-)$ with the assignment of $\mathrm{LF}$ transitions in the LS and the HS state (left axis - adapted from Ref. [4]). Variable temperature (10 K intervals) absorption spectra of [ $\mathrm{Zn}_{1-}$ $\left.{ }_{x} \mathrm{Fe}_{\mathrm{x}}(\mathrm{ptz})_{6}\right]\left(\mathrm{BF}_{4}\right)_{2}, \mathrm{x}=0.01$, in the region of the MLCT transitions (right axis).

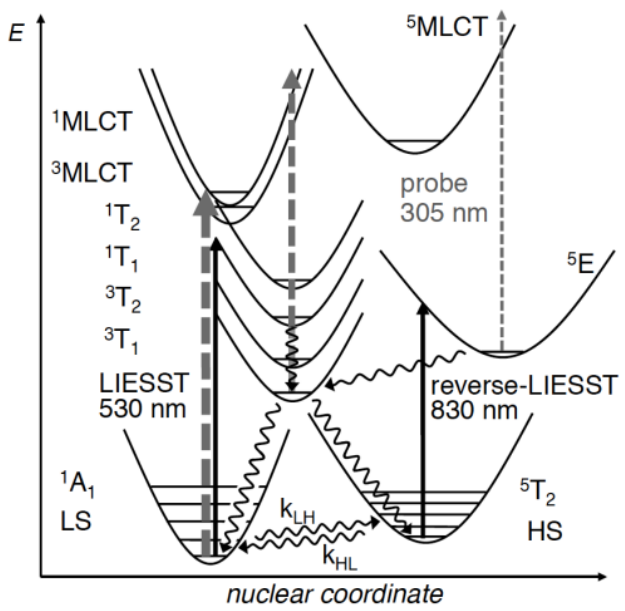

Figure 2. Schematic representation of the electronic structure of iron(II) spin-crossover compounds with only high-energy MLCT states. LIESST $\left(\lambda_{\text {ex }}=530 \mathrm{~nm}\right)$ and reverse-LIESST $\left(\lambda_{\text {ex }}=830 \mathrm{~nm}\right)$ via the LF states as in $\left[\mathrm{Fe}(\mathrm{ptz})_{6}\right]\left(\mathrm{BF}_{4}\right)_{2}$ are indicated by curly arrows. The $305 \mathrm{~nm}$ probe $(---)$ monitors the MLCT transitions. 


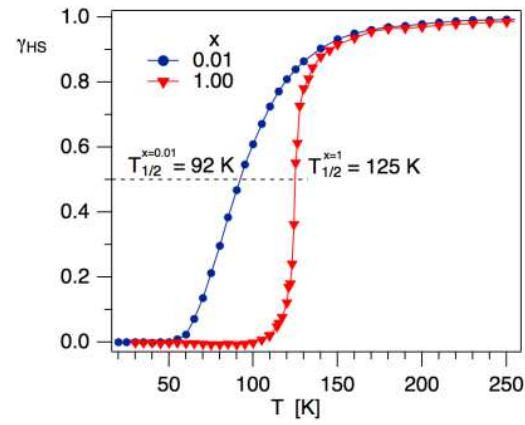

Figure 3. Spin transition curves for $\left[\mathrm{Fe}(\mathrm{ptz})_{6}\right]\left(\mathrm{BF}_{4}\right)_{2}$ in the crystallographic high-temperature phase $(\nabla)$, and in $\left[\mathrm{Zn}_{1-\mathrm{x}} \mathrm{Fe}_{\mathrm{x}}\left(\mathrm{ptz}_{6}\right](\mathrm{BF})_{4}, \mathrm{x}=0.01(\bullet)\right.$
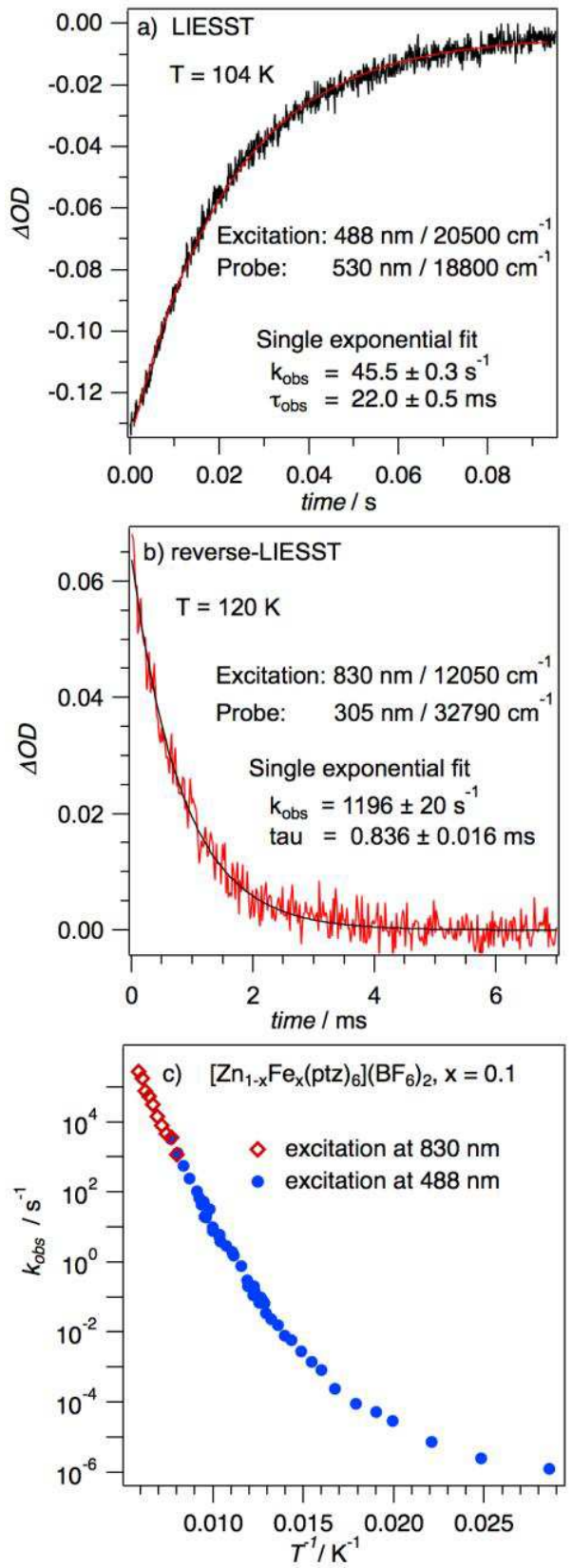

Figure 4. The HS $\Pi$ LS relaxation in $\left[\mathrm{Zn}_{1-\mathrm{x}} \mathrm{Fe}_{\mathrm{x}}\left(\mathrm{ptz}_{6}\right]\left(\mathrm{BF}_{4}\right)_{2}, \mathrm{x}=0.1\right.$ : a) transient absorption at $530 \mathrm{~nm}$ for $\lambda_{\text {ex }}=488 \mathrm{~nm}$ at $104 \mathrm{~K}(\mathrm{LIESST})$; $\mathrm{b}$ ) transient absorption at $305 \mathrm{~nm}$ for $\lambda_{\mathrm{ex}}=830 \mathrm{~nm}$ and $120 \mathrm{~K}$ (reverse-LIESST); c) observed relaxation rate constant $\mathrm{k}_{\mathrm{obs}}=\mathrm{k}_{\mathrm{HL}}+\mathrm{k}_{\mathrm{LH}} \mathrm{vs}_{\mathrm{S}} \mathrm{T}^{-1}$ on a logarithmic scale, $(\bullet) \lambda_{\mathrm{ex}}=488 \mathrm{~nm}$ (taken from Ref. [4]) and $(\bullet) \lambda_{\mathrm{ex}}=830 \mathrm{~nm}$. 

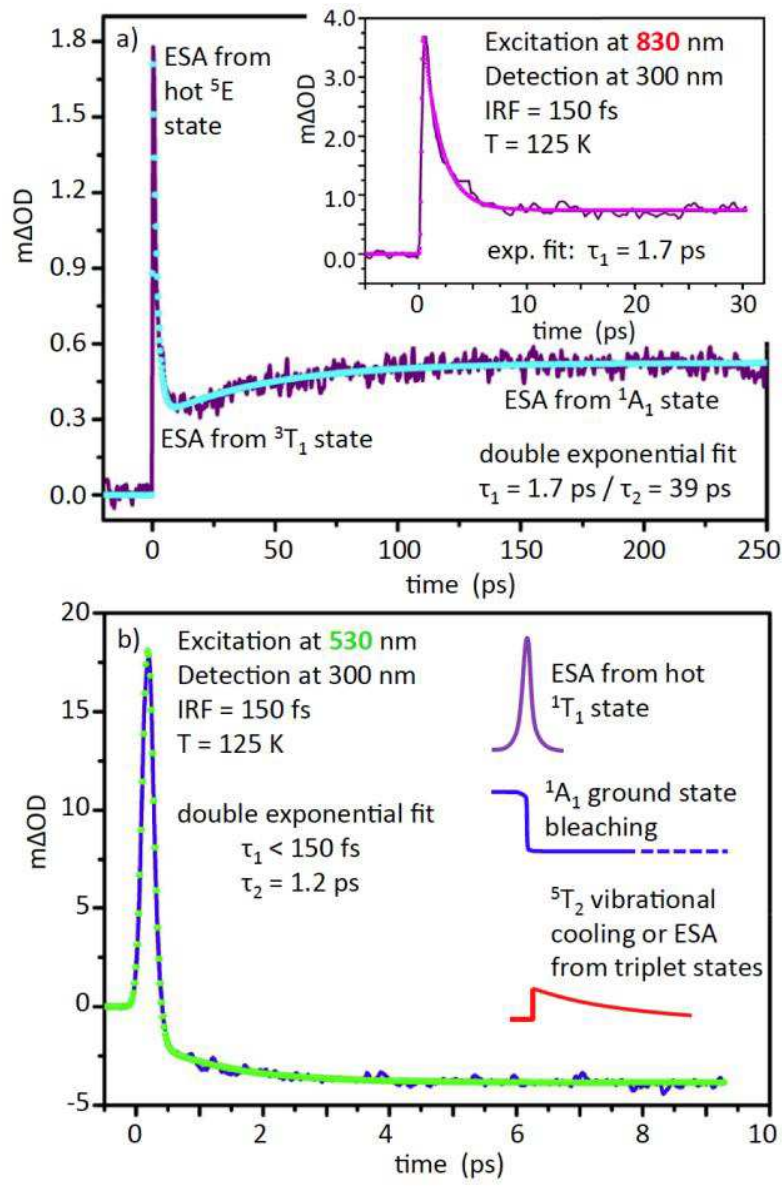

Figure 5. Ultrafast transient absorption profiles for $\left[\mathrm{Zn}_{1-\mathrm{x}} \mathrm{Fe}_{\mathrm{x}}\left(\mathrm{ptz}_{6}\right)_{6}\left(\mathrm{BF}_{4}\right)_{2}, \mathrm{x}=0.1\right.$, at $125 \mathrm{~K}$ for a) $\lambda_{\mathrm{ex}}=830 \mathrm{~nm}\left(12050 \mathrm{~cm}^{-1}\right)$, and b) $\lambda_{\mathrm{ex}}=530 \mathrm{~nm}$ $\left(18800 \mathrm{~cm}^{-1}\right)$, both monitored at $300 \mathrm{~nm}\left(33330 \mathrm{~cm}^{-1}\right)$. In b) the decomposition of the contributions to the transient signal is indicated schematically. 